Article

\title{
Evaluation of the Ocean Surface Wind Speed Change following the Super Typhoon from Space-Borne GNSS-Reflectometry
}

\author{
Hongsu Liu ${ }^{1}$, Shuanggen Jin ${ }^{1,2,3, * \mathbb{D}}$ and Qingyun Yan ${ }^{1}(\mathbb{D}$ \\ 1 School of Remote Sensing and Geomatics Engineering, Nanjing University of Information Science and \\ Technology, Nanjing 210044, China; 20181211007@nuist.edu.cn (H.L.); qy2543@mun.ca (Q.Y.) \\ 2 Shanghai Astronomical Observatory, Chinese Academy of Sciences, Shanghai 200030, China \\ 3 Jiangsu Engineering Center for Collaborative Navigation/Positioning and Smart Applications, \\ Nanjing 210044, China \\ * Correspondence: sgjin@nuist.edu.cn
}

Received: 20 May 2020; Accepted: 22 June 2020; Published: 24 June 2020

\begin{abstract}
Ocean surface wind speed is an essential parameter for typhoon monitoring and forecasting. However, traditional satellite and buoy observations are difficult to monitor the typhoon due to high cost and low temporal-spatial resolution. With the development of spaceborne GNSS-R technology, the cyclone global navigation satellite system (CYGNSS) with eight satellites in low-earth orbit provides an opportunity to measure the ocean surface wind speed of typhoons. Though observations are made at the extremely efficient spatial and temporal resolution, its accuracy and reliability are unclear in an actual super typhoon case. In this study, the wind speed variations over the life cycle of the 2018 Typhoon Mangkhut from CYGNSS observations were evaluated and compared with European Centre for Medium-Range Weather Forecasts (ECMWF) Re-Analysis-5 (ERA-5). The results show that the overall root-mean-square error (RMSE) of CYGNSS versus ECMWF was $4.12 \mathrm{~m} / \mathrm{s}$, the mean error was $1.36 \mathrm{~m} / \mathrm{s}$, and the correlation coefficient was 0.96 . For wind speeds lower and greater than $15 \mathrm{~m} / \mathrm{s}$, the RMSE of CYGNSS versus ECMWF were 1.02 and $4.36 \mathrm{~m} / \mathrm{s}$, the mean errors were 0.05 and $1.61 \mathrm{~m} / \mathrm{s}$, the correlation coefficients were 0.91 and 0.90 , and the average relative errors were $9.8 \%$ and $11.6 \%$, respectively. When the typhoon reached a strong typhoon or super typhoon, the RMSE of CYGNSS with respect to ERA-5 from ECMWF was $5.07 \mathrm{~m} / \mathrm{s}$; the mean error was $3.57 \mathrm{~m} / \mathrm{s}$; the correlation coefficient was 0.52 and the average relative error was $11.0 \%$. The CYGNSS estimation had higher precision for wind speeds below $15 \mathrm{~m} / \mathrm{s}$, but degraded when the wind speed was above $15 \mathrm{~m} / \mathrm{s}$.
\end{abstract}

Keywords: CYGNSS; ECMWF; GNSS-R; typhoon; ocean surface wind field

\section{Introduction}

As an extreme weather phenomenon, the typhoon can bring severe storms and heavy rains, which can cause devastating damage to human life and property. In recent years, the frequency of typhoons has shown an upward trend [1], so the requirements for accurate typhoon monitoring and prompt early warning are urgent, while the predictions of the typhoon intensity are still difficult till now [2]. In the current study, one of the key issues is lack of precise wind speed observation near the center of typhoon to help understanding of its physical process in-depth [3]. Optical remote sensing satellite signal are blocked by the cloud and heavy rainfall inside the typhoon, resulting in the absence of accurate and frequent observations of wind field in the typhoon inner core [4].

With the development of Global Navigation Satellite System (GNSS) [5], the GNSS-reflectometry (GNSS-R) technology has been widely used for various geophysical parameters remote sensing, 
including ocean wave height and speed estimation. At the same time, GNSS-R has numerous advantages, including global coverage, low cost, all-weather and near real time [6]. In particular, GNSS L-band signals can penetrate clouds and heavy rainfall under any type of weather conditions so it is useful to monitor ocean wind speeds during a typhoon event [7]. Cyclone Global Navigation Satellite System (CYGNSS) uses the GPS signals reflected from the ocean surface to detect wind speed [8] at high-temporal resolution, which may improve the forecast of the tropical cyclone's intensity [9]. Figure 1 shows the sub-satellite point tracks of one CYGNSS satellite and eight CYGNSS satellites for 24 hours. Since the eight satellites of CYGNSS can work at the same time, CYGNSS can measure the ocean surface winds between $38^{\circ} \mathrm{N}$ and $38^{\circ} \mathrm{S}$ in latitude with high spatial resolution [10].

(a) Sub-satellite point tracks of satellite CYO1

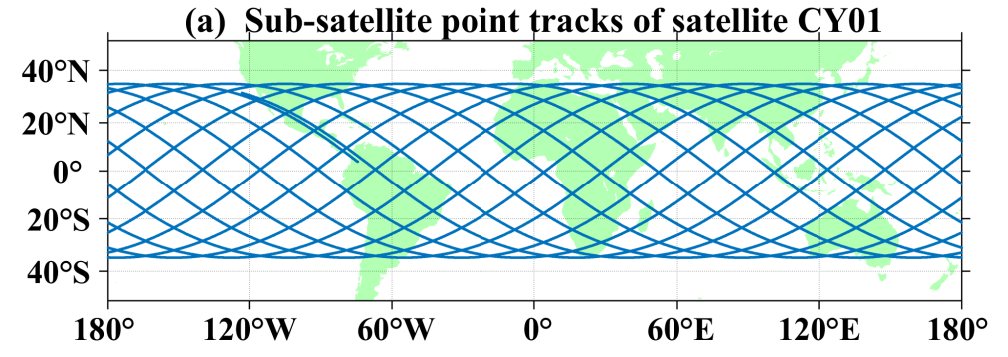

(b) Sub-satellite point tracks of eight satellites

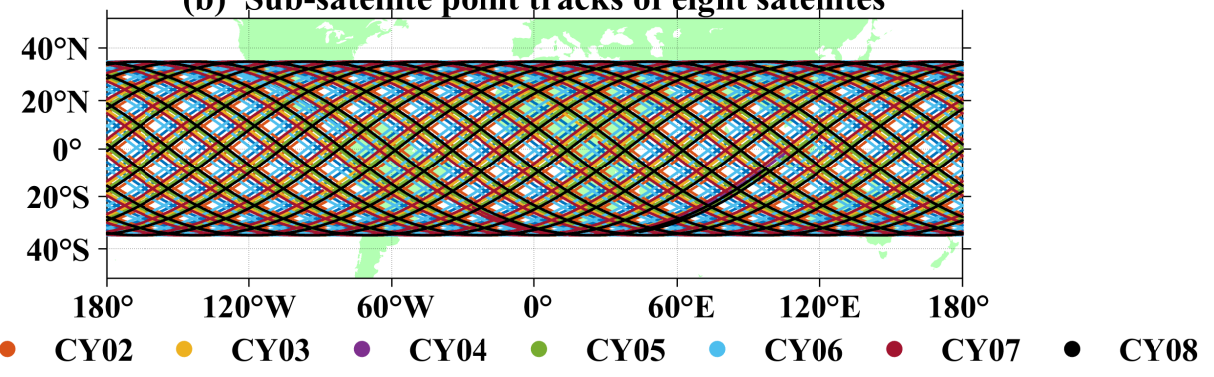

Figure 1. Tracks of one and eight CYGNSS sub-satellites. (a) Sub-satellite point tracks of one cyclone global navigation satellite system (CYGNSS) satellite for 24 hours; (b) sub-satellite point tracks of eight CYGNSS satellites for 24 hours.

The sea surface wind speed inversion and tropical cyclone forecasting have been achieved from CYGNSS data. Cui et al. [11] assimilated CYGNSS wind speed data into the numerical model and showed an improved prediction accuracy of the intensity, track and structure of two tropical cyclones. The average improvement rate of hurricane track and intensity was around 20\%, and the location of maximum wind bands wrap was consistent with the radar analysis. Hoover et al. [12] used end-to-end simulators to generate simulated CYGNSS data and assimilate it into the weather research and forecasting (WRF) dataset. The results showed that CYGNSS could maintain good wind field detection capability even under the influence of heavy rainfall, indicating the great potential of CYGNSS in tropical cyclone monitoring. Saïd et al. [13] developed a new method to estimate the maximum wind speed of hurricanes by using CYGNSS data. The results showed that when the maximum wind speed was less than $40 \mathrm{~m} / \mathrm{s}$, the wind speed deviations by comparing the new method with the best track and hurricane weather research and forecasting (HWRF) model are 8.6 and $9 \mathrm{~m} / \mathrm{s}$, respectively. Shi and Zhao [14] used CYGNSS to simulate hurricane prediction, and the results showed that assimilation of CYGNSS could improve the accuracy of hurricane track and intensity prediction, and provide a better representation of the dynamic and thermodynamic structure and surface fluxes in the hurricane inner-core region.

A number of studies have been carried out using CYGNSS dataset, however, the previous evaluation and analysis of CYGNSS wind speed are mainly conducted on simulated storms or limited certain stage in the tropical cyclone. Furthermore, its accuracy and reliability are not verified in the 
actual super typhoon cases. In this study, the accuracy of CYGNSS wind speed is evaluated throughout the life cycle of the super typhoon Mangkhut, the 22nd typhoon of the 2018 Pacific typhoon season, and the wind speed change trend as well as the temporal and spatial variation characteristics of the ocean surface wind field are analyzed. Section 2 shows the super Typhoon Mangkhut information, methodology of CYGNSS wind estimation and the data processing. In Section 3, results and discussion are presented by comparing with the ECMWF reanalysis dataset [15]. Finally conclusions are given in Section 4.

\section{Data and Methods}

\subsection{Typhoon Mangkhut}

The definition of a super typhoon is that the sustained wind speed near the center of the tropical cyclone reaches $51 \mathrm{~m} / \mathrm{s}$. Mangkhut (Typhoon \# 201822) was a super typhoon formed in early September 2018. At 8:00 pm on September 7th, Mangkhut was upgraded to a tropical depression, though being influenced by the subtropical high, the development of Mangkhut was very slow. Due to environmental factors such as high sea surface temperatures, weak wind shear and excellent upper air divergence, the subsequent development of the typhoon was ensured. From September 7th to 9th 2018, Mangkhut gradually developed from a tropical depression into a typhoon.

Mangkhut explosively enhanced to a super typhoon in the early morning of September 11th. Later, it entered the "eyewall replacement" cycle on the evening of September 12th and the afternoon of September 14th, leading to a slight decrease in intensity. Mangkhut made landfall in the Philippines at 1:00 am on September 15th. During the landing period, the structure of Mangkhut was destroyed and the wind speed decreased. Furthermore, it left Philippines and entered the South China Sea. In this zone, the circulation structure of the typhoon was reorganized, but its intensity was reduced compared to before landing in the Philippines and was downgraded to a strong typhoon at 9:00 am on September 15th.

At 5:00 pm on September 16th, Mangkhut made landfall in Haiyan town, Guangdong Province, China, as a strong typhoon. At 5:00 pm on September 17th, Mangkhut further decreased in strength, and gradually weakened to tropical depression level.

\subsection{CYGNSS Data and Processing}

NASA launched the CYGNSS in 2016. The CYGNSS uses GPS signals reflected from the ocean surface [16] to measure wind speeds. Because CYGNSS can measure wind speed of sea surface and typhoon inner core under extreme weather conditions, so it can improve the accuracy of tropical cyclone prediction [17]. The CYGNSS constellation comprises eight small satellites with an orbital inclination of $35^{\circ}, 510 \mathrm{~km}$ height, and $25 \mathrm{~km} \times 25 \mathrm{~km}$ spatial resolution [18].

CYGNSS equipped Delay Doppler Mapping Instrument (DDMI). CYGNSS calibrates the received original signal from DDMI to Delay-Doppler map (DDM), after two levels of DDM calibration, two observations called delay-Doppler map average (DDMA) and leading-edge slope (LES) can be deduced from DDM. DDMA is the average value of DDM within a given delay and Doppler frequency range and LES is the slope of the leading edge of the integrated delay waveform (IDW) [19]. Because each observation has a certain mapping relationship with the sea surface wind speed, so the independent GMF empirical formula with wind speed is established by using DDMA and LES separately, and then the GMF can calculate the wind speed corresponding to each DDMA and LES. Finally, the wind speed calculated by each individual GMF formula is combined to produce minimum variance (MV) estimator, which can obtain higher quality wind speed estimation by minimizing the RMS error of the original retrieved wind speeds [20].

In this study, we used the L2 CYGNSS wind speed product for analysis. Here the L2 Young Seas/Limited Fetch (YSLF) wind speed products of the CYGNSS 2.1 version were used from PO.DAAC (https://doi.org/10.5067/CYGNS-L2X21). Before using CYGNSS wind speed data for evaluation, it was 
necessary to remove invalid and low-quality data through quality control. Another step in screening out high quality data was based on the range-corrected gain (RCG) thresholds under different wind speed conditions. In general, RCG could represent the strength of the received signal: a higher RCG represents better quality data, considering the influence of antenna and distance on the signal [21]. When the wind speed was less than $15 \mathrm{~m} / \mathrm{s}$, the RCG threshold was set to 5 or more and when the wind speed exceeds $15 \mathrm{~m} / \mathrm{s}$, the data with RCG more than 10 was selected as sample points.

\subsection{ECMWF and Typhoon Track Data}

ECMWF reanalysis data are available from the Copernicus climate change service (C3S) climate data store (https://cds.climate.copernicus.eu/cdsapp\#!/home). The ERA-5 reanalysis data of ECMWF [22] provide hour-by-hour information on global sea surface wind speeds. Typhoon track information can be available from China typhoon network (https://www.typhoon.org.cn/), which provides information on the latitude and longitude of the typhoon center and the maximum wind speed of the typhoon.

\subsection{Evaluation Methods}

CYGNSS was compared with ERA-5 reanalysis data of ECMWF. The RMSE, mean error and the Pearson correlation coefficient (R) were used to evaluate CYGNSS wind speed products. For wind speeds below and above $15 \mathrm{~m} / \mathrm{s}$, the relative error and mean absolute error (MAE) was used to evaluate the observation accuracy of CYGNSS. The formulas for evaluating the accuracy of wind speed were as follows:

$$
\begin{gathered}
\text { RMSE }=\sqrt{\frac{1}{N} \sum_{i=1}^{N}\left(A_{i}-B_{i}\right)^{2}}, \\
\text { mean error }=\frac{1}{N} \sum_{i=1}^{N}\left(A_{i}-B_{i}\right), \\
\mathrm{MAE}=\frac{1}{N} \sum_{i=1}^{N}\left(\left|A_{i}-B_{i}\right|\right), \\
\mathrm{R}=\frac{\sum_{i=1}^{N}\left(A_{i}-A_{m}\right)\left(B_{i}-B_{m}\right)}{\sqrt{\sum_{i=1}^{N}\left(A_{i}-A_{m}\right)^{2} \sum_{i=1}^{N}\left(B_{i}-B_{m}\right)^{2}}}, \\
\text { relative error }=\left(\frac{\left|A_{i}-B_{i}\right|}{B_{i}}\right) \times 100 \%,
\end{gathered}
$$

where $N$ is the total number of sampling points, $A_{i}$ is the CYGNSS wind speed, $A_{m}$ is the average wind speed of CYGNSS, $B_{i}$ is the wind speed of ERA-5 reanalysis data and $B_{m}$ is the average wind speed of the ERA-5 reanalysis data.

\section{Results and Discussion}

\subsection{Evaluation by ERA-5 Data}

The ECMWF assimilated meteorological data from different sources to obtain the ERA-5 reanalysis dataset, which included the wind speed of $10 \mathrm{~m}$ height above the sea surface, so we compared the wind speed of ECMWF reanalysis data with the CYGNSS inversion results. The track of CYGNSS and the location of the typhoon center are shown in Figure 2. The orange line represents the CYGNSS track, the black dot represents the typhoon center and the green patch represents the land.

In view of the difference in observation time, the CYGNSS and ERA- 5 data were matched up within 20 minutes. A $2^{\circ} \times 2^{\circ}$ spatial grid was constructed from the longitude and latitude of the typhoon center. Within this space grid, we find the matched data columns of CYGNSS with ECMWF reanalysis data at the same time. The spatial resolution of CYGNSS was $0.2^{\circ} \times 0.2^{\circ}$ and the resolution of the ECMWF reanalysis data were $0.25^{\circ} \times 0.25^{\circ}$. In order to get more matching points of CYGNSS and ECMWF for comparison, we had adopted the method of biharmonic spline interpolation for the 
CYGNSS and ECMWF reanalysis data and the spatial resolution after interpolation was unified to $0.1^{\circ} \times 0.1^{\circ}$

(a) Relative position of CYGNSS track and typhoon center
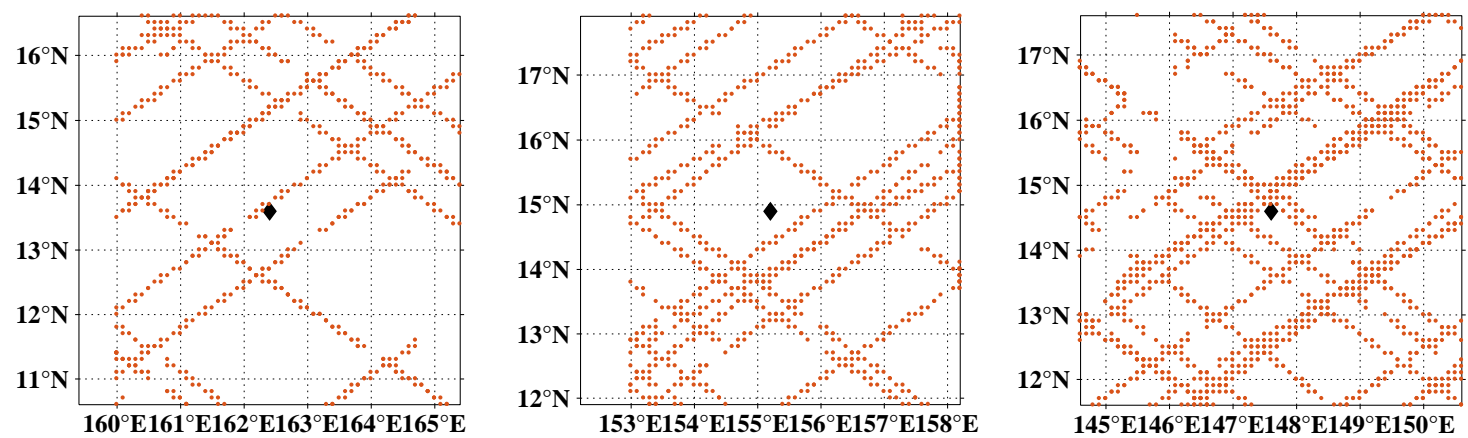

(b) Relative position of CYGNSS track and typhoon center
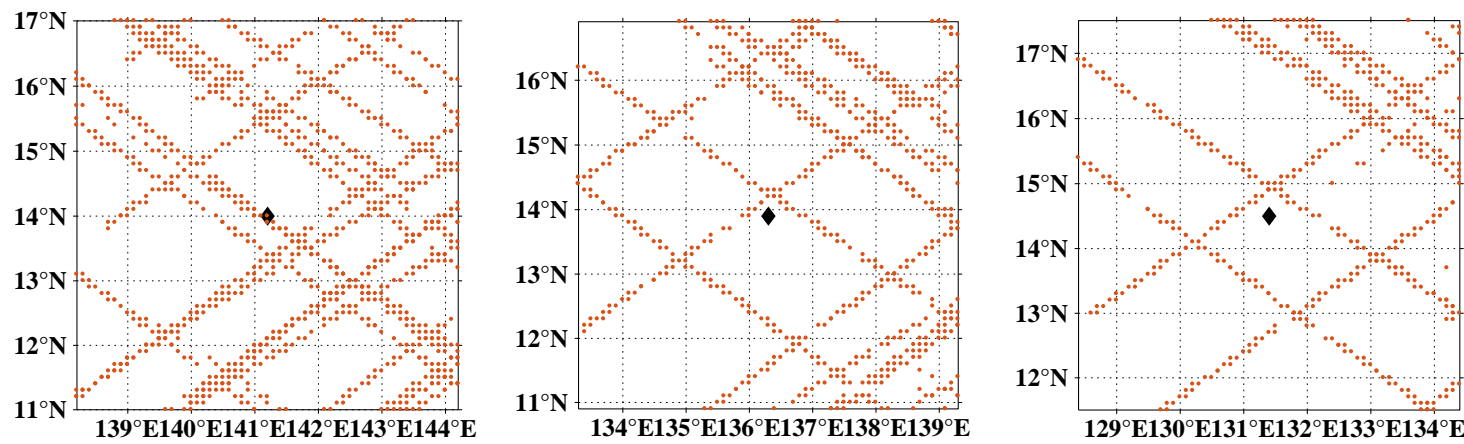

(c) Relative position of CYGNSS track and typhoon center
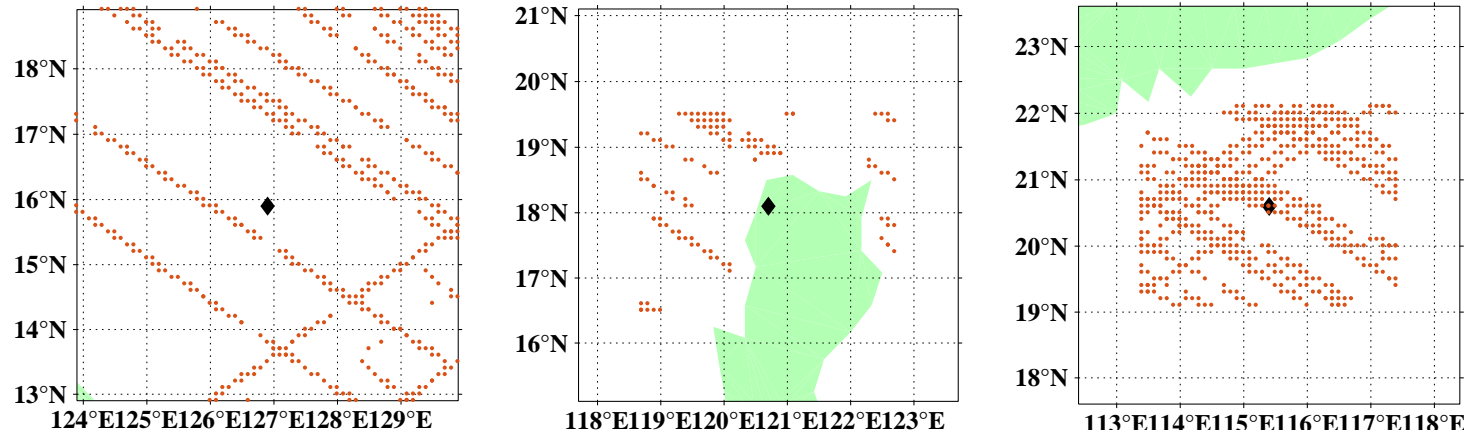

Figure 2. Specular point tracks and typhoon center position. The relative position of the CYGNSS track and the typhoon center from September 8 th to September 16th. The orange line represents the CYGNSS track, the black dot represents the typhoon center and the green patch represents the Earth's land.

From September 8th to September 16th, at the same time of day, the collocated CYGNSS and ECMWF reanalysis data at the same latitude and longitude were enabled to be compared. The comparison results are shown in Figure 3.

The correlation analysis was conducted between the CYGNSS data and the ERA-5 reanalysis data of ECMWF. Figure 3a shows the correlation coefficient and $(\mathrm{R}=0.96)$. The overall RMSE is $4.12 \mathrm{~m} / \mathrm{s}$ and the mean error between the CYGNSS and ECMWF observation is $1.36 \mathrm{~m} / \mathrm{s}$. The color bar represents the data density in a certain range. The histogram of residual distribution was shown in Figure 3b, where the highest residual density is generally distributed near zero. The error sources of CYGNSS wind speeds and ECMWF reanalysis data mainly include: 
(1) The time resolutions of CYGNSS and ECMWF reanalysis data are not exactly the same. The matching of some sample points is based on extremely approximate time, which may leads to the difference in wind speed.

(2) The ERA-5 is reanalysis data with assimilating a large number of historical data from different sources, which has some errors with large uncertainty.

\section{(a) CYGNSS and ECMWF correlation analysis}

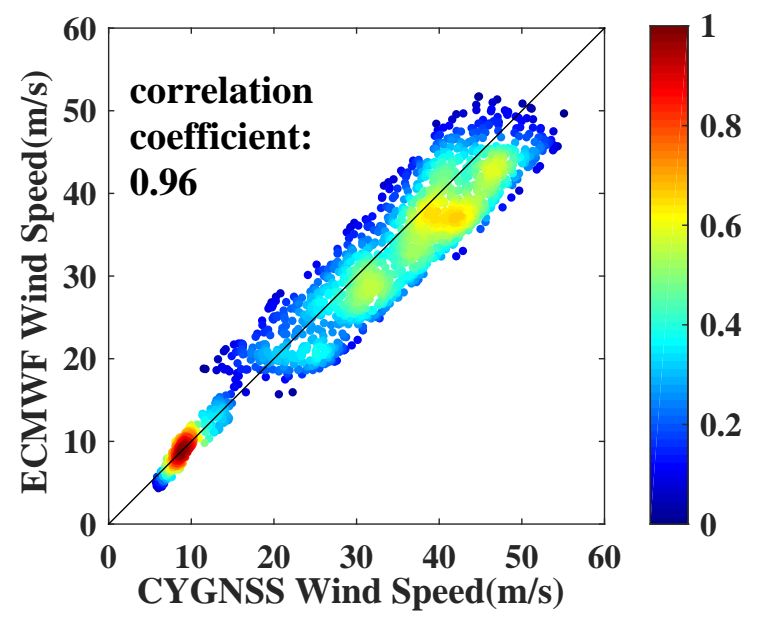

(b) Residual histogram

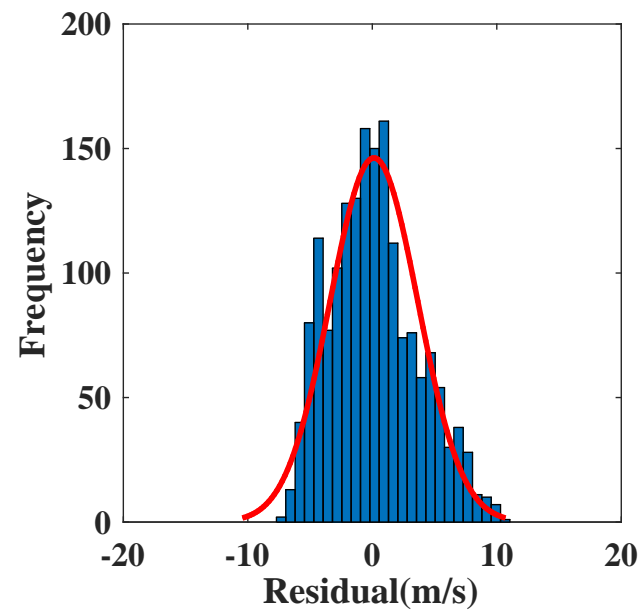

Figure 3. Scatter density plot and residual distribution of CYGNSS and ECMWF wind speeds. (a) Scatter plot of CYGNSS and European Centre for Medium-Range Weather Forecasts (ECMWF) wind; (b) CYGNSS and ECMWF wind-speed residual distribution histogram.

\subsection{Variations of Sea Surface Wind Speed}

According to the longitude and latitude data of the Typhoon Mangkhut and the information on the typhoon evolution is obtained from the National Meteorological Center of CMA. With the help of the relevant information of the Hong Kong Observatory (https://www.hko.gov.hk/en/informtc/ mangkhut18/maxWind.htm), CYGNSS and ECMWF reanalysis data at sample points were compared in the variation trend of the sea surface wind speed.

In the wind speed inversion error from $-10 \mathrm{~m} / \mathrm{s}$ to $10 \mathrm{~m} / \mathrm{s}$, the Probability density functions (PDF) of all wind speed sample points and wind speed less /greater than $15 \mathrm{~m} / \mathrm{s}$ are calculated, which are shown in Figure 4. It can be seen that when the wind speed increases, the positive errors are more than the negative errors, which shows that CYGNSS overestimates the wind speed values when the wind speed is large.

From September 8th to September 16th, the sample points after interpolation are sorted according to the distance from the typhoon center, and the Euclidean metric is used to indicate the distance between the sample points and the typhoon center, and the variation of sea surface wind speed in different life stages of typhoon is analyzed. The time of comparison was 8:00 am every morning from September 8th to September 16th. On September 8th, the average sea surface wind speed of sample points from CYGNSS and ECMWF reanalysis data were $8.5 \mathrm{~m} / \mathrm{s}$ and $8.4 \mathrm{~m} / \mathrm{s}$, respectively, and the peak wind speed of sample points reached $10.3 \mathrm{~m} / \mathrm{s}$ and $11.8 \mathrm{~m} / \mathrm{s}$, respectively.

On September 9th, due to the high sea surface temperature, weak vertical wind shear and excellent upper air divergence, Mangkhut began to increase in intensity. It was upgraded to a severe tropical storm in the early morning of September 9th and was upgraded to "typhoon" at 8:00 am. The average sea surface wind speeds of sample points from CYGNSS and ECMWF reanalysis data were $12.8 \mathrm{~m} / \mathrm{s}$ and $13.0 \mathrm{~m} / \mathrm{s}$, respectively, and the peak wind speeds of sample points were $15.7 \mathrm{~m} / \mathrm{s}$ and $16.9 \mathrm{~m} / \mathrm{s}$, respectively. 
Probability Density Function of wind speed inversion errors

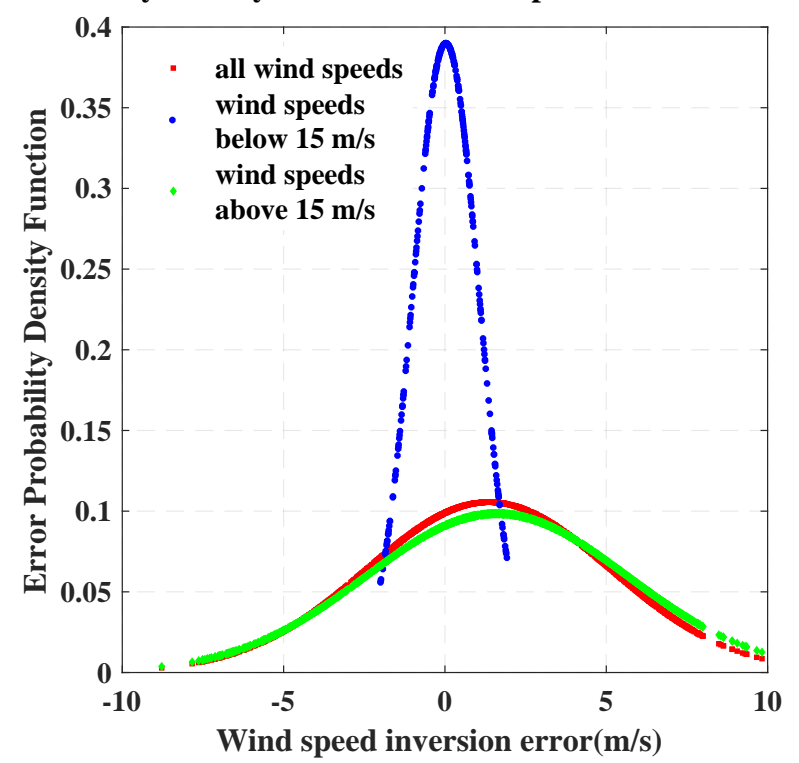

Figure 4. Probability density function of wind speed inversion errors.

On September 10th, the typhoon moved to the sea with strong wind shear and its development was restrained due to the invasion of high-level dry air. However, it was still upgraded to the level of "strong typhoon" at 8:00 pm. The average sea surface wind speeds of sample points from CYGNSS and ECMWF reanalysis data were $27.6 \mathrm{~m} / \mathrm{s}$ and $27.5 \mathrm{~m} / \mathrm{s}$, respectively, and the peak wind speeds of sample points reached $33.8 \mathrm{~m} / \mathrm{s}$ and $33.4 \mathrm{~m} / \mathrm{s}$, respectively. The comparison from September 8th to September 10th is shown in Figure 5a. The $x$-axis represents the number of sample points per day, and the $y$-axis represents the wind speed.

(a) Sea surface wind speeds time series of typhoon from September 8th to 10th
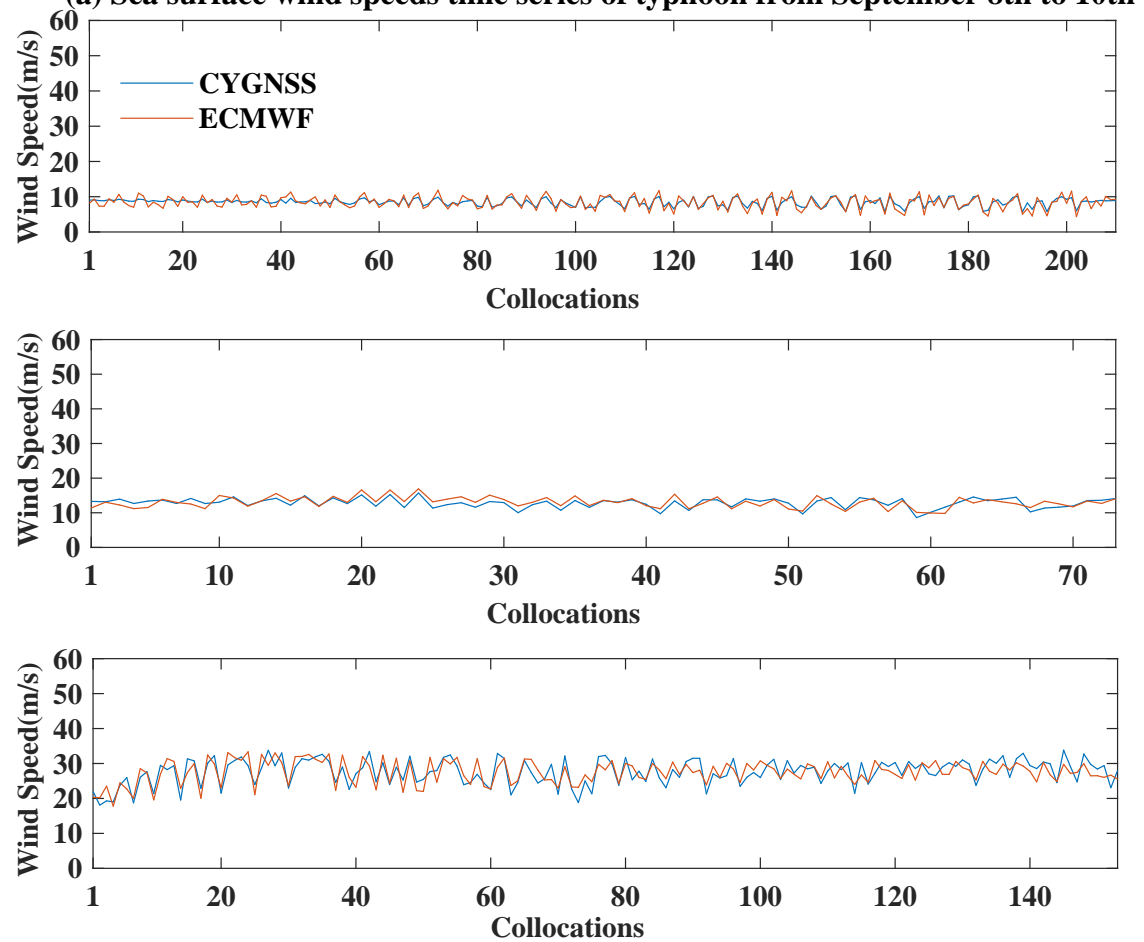

Figure 5. Cont. 
(b) Sea surface wind speeds time series of typhoon from September 11th to 13th
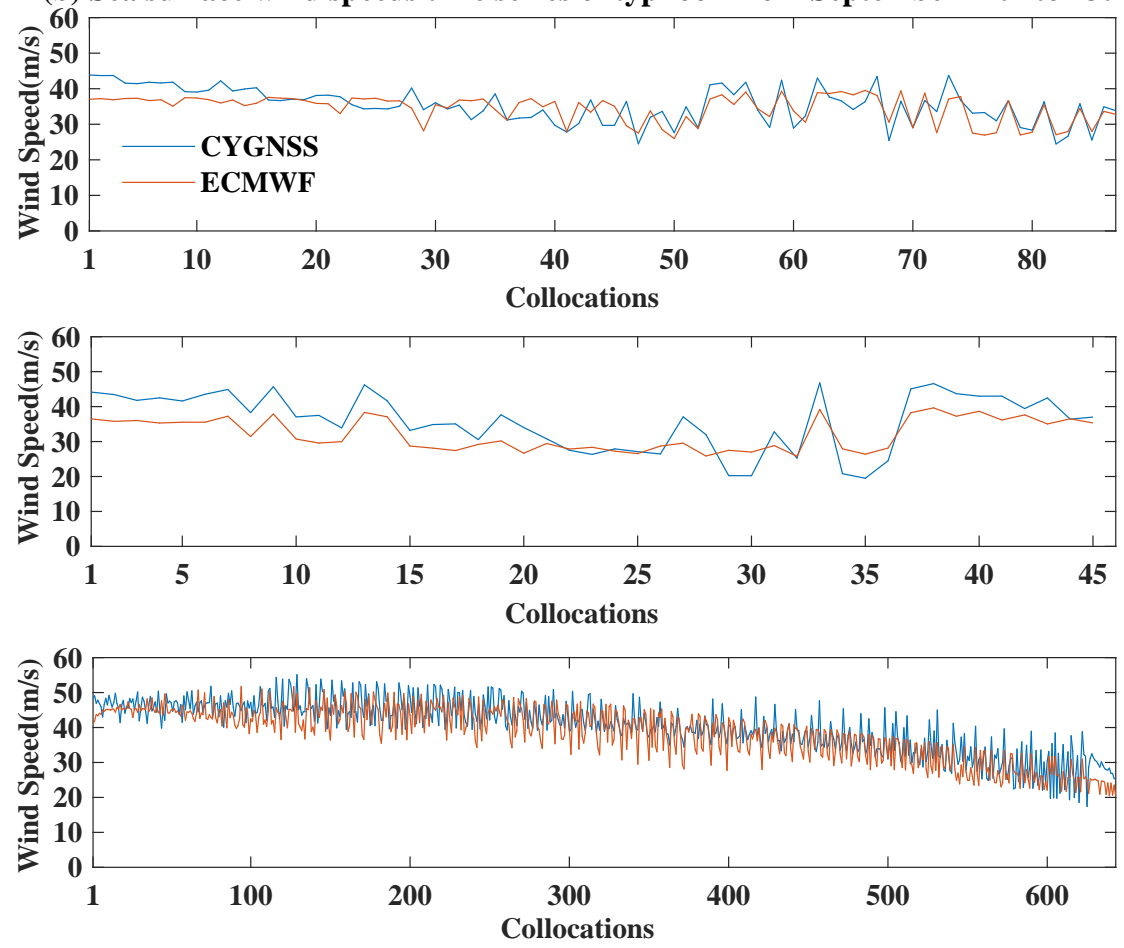

(c) Sea surface wind speeds time series of typhoon from September 14th to 16th
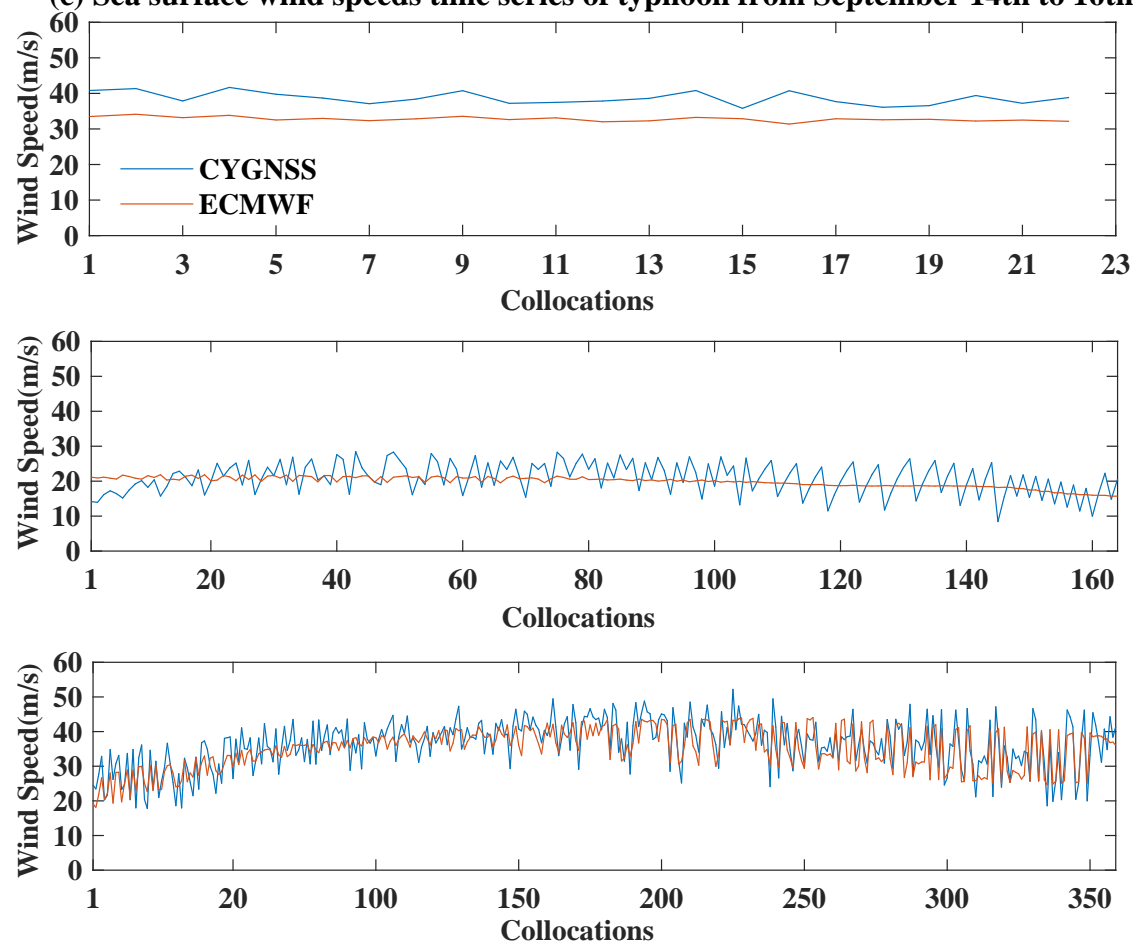

Figure 5. Comparison of sea surface wind speed between CYGNSS and ECMWF reanalysis data. (a) From September 8th to September 10th, (b) from September 11th to September 13th; (c) from September 14th to September 16th. The $x$-axis represents the number of sample points per day and the $y$-axis represents the wind speed.

When it is upgraded to "super typhoon" in the morning on September 11th, the average sea surface wind speeds of sample points from CYGNSS and ECMWF reanalysis data were $35.4 \mathrm{~m} / \mathrm{s}$ and $34.5 \mathrm{~m} / \mathrm{s}$, respectively, and the peak wind speeds of sample points were $43.9 \mathrm{~m} / \mathrm{s}$ and $39.5 \mathrm{~m} / \mathrm{s}$, respectively. 
From September 12th to 14th, the Mangkhut developed steadily and always keep the level of a super typhoon. On the evening of the September 12th, the typhoon entered the "eyewall replacement" cycle, which led to a slight decrease of the wind speed, but the overall intensity was still rising. The average sea surface wind speeds of sample points from CYGNSS and ECMWF reanalysis data on the September 12th were $35.8 \mathrm{~m} / \mathrm{s}$ and $32.1 \mathrm{~m} / \mathrm{s}$, respectively. The peak wind speeds of sample points reached $46.8 \mathrm{~m} / \mathrm{s}$ and $39.6 \mathrm{~m} / \mathrm{s}$, respectively.

On September 13th, the typhoon continued to move towards the northwest. The average sea surface wind speeds of sample points from CYGNSS and ECMWF reanalysis data were $40.5 \mathrm{~m} / \mathrm{s}$ and $38.3 \mathrm{~m} / \mathrm{s}$, respectively, and the peak wind speeds of sample points reached $55.1 \mathrm{~m} / \mathrm{s}$ and $51.7 \mathrm{~m} / \mathrm{s}$. The comparison from September 11th to September 13th is shown in Figure 5b.

On September 14th, the typhoon entered the "eyewall replacement" cycle again, and the typhoon intensity has decreased. The average sea surface wind speeds of sample points from CYGNSS and ECMWF reanalysis data were $38.7 \mathrm{~m} / \mathrm{s}$ and $32.8 \mathrm{~m} / \mathrm{s}$, respectively, and the peak wind speeds of sample points were $41.7 \mathrm{~m} / \mathrm{s}$ and $34.1 \mathrm{~m} / \mathrm{s}$, respectively. On the early morning of September 15th, Mangkhut made landfall in the Philippines. Due to the influence of topography, the typhoon structure was damaged, and the intensity was weakened. At 8:00 am, the average sea surface wind speed of sample points from CYGNSS and ECMWF reanalysis data were $20.8 \mathrm{~m} / \mathrm{s}$ and $19.8 \mathrm{~m} / \mathrm{s}$, respectively, and the peak wind speed of sample points reached $28.5 \mathrm{~m} / \mathrm{s}$ and $21.8 \mathrm{~m} / \mathrm{s}$, respectively. Then the typhoon entered the South China Sea and the circulation structure of Mangkhut in the South China Sea was reorganized, leading to a rebound in typhoon strength and wind speed. On the 8:00 am of the September 16th, the average sea surface wind speeds of sample points from CYGNSS and ECMWF reanalysis data were $36.4 \mathrm{~m} / \mathrm{s}$ and $35 \mathrm{~m} / \mathrm{s}$, respectively, the peak wind speeds of sample points reached $52.2 \mathrm{~m} / \mathrm{s}$ and $44.1 \mathrm{~m} / \mathrm{s}$, respectively. The comparison from September 14th to September 16th is shown in Figure 5c.

Mangkhut made landfall in Guangdong as a "strong typhoon" on the afternoon of the September 16th, and then the Mangkhut typhoon deeply penetrated inland regions. Due to the impact with topographic factors, the intensity continued to weaken and gradually dissipated.

The average and maximum wind speeds of CYGNSS and ECMWF reanalysis data during the development of typhoon are given in Table 1, and the latitude and longitude of the maximum wind speed are given in Table 2. The different stages of Typhoon Mangkhut are shown in Table 1, clearly showing the average and maximum wind speeds of CYGNSS and ECMWF reanalysis data in the matched sample points. The average value of wind speed was obtained by averaging the sample points at each stage. It can be seen from Table 2, among all the sample points, the longitude and latitude of the maximum wind speed obtained by CYGNSS and ECMWF reanalysis data were basically similar. From Figure $5 a-c$, when the wind speed of these sample points was lower than $15 \mathrm{~m} / \mathrm{s}$, the wind speeds given by CYGNSS and ECMWF reanalysis data were generally in good agreement, but there is a difference when the wind speed was above $15 \mathrm{~m} / \mathrm{s}$.

Table 1. Comparison of average and maximum wind speeds from CYGNSS and ECMWF.

\begin{tabular}{|c|c|c|c|c|c|}
\hline Date & $\begin{array}{c}\text { Typhoon } \\
\text { Development Stage }\end{array}$ & $\begin{array}{c}\text { CYGNSS/ECMWF Average } \\
\text { Wind Speed }(\mathrm{m} / \mathrm{s})\end{array}$ & $\begin{array}{c}\text { Deviation } \\
(\mathrm{m} / \mathrm{s})\end{array}$ & $\begin{array}{c}\text { CYGNSS/ECMWF } \\
\text { Maximum Wind Speed (m/s) }\end{array}$ & $\begin{array}{c}\text { Deviation } \\
(\mathrm{m} / \mathrm{s})\end{array}$ \\
\hline September 8th & Severe tropical storm & $8.5 / 8.4$ & 0.1 & $10.3 / 11.8$ & -1.5 \\
\hline September 9th & typhoon & $12.8 / 13$ & -0.2 & $15.7 / 16.9$ & -1.2 \\
\hline September 10th & typhoon & $27.6 / 27.5$ & 0.1 & $33.8 / 33.4$ & 0.4 \\
\hline September 11th & Super typhoon & $35.4 / 34.5$ & 0.9 & $43.9 / 39.5$ & 4.4 \\
\hline September 12th & Super typhoon & $35.8 / 32.1$ & 3.7 & $46.8 / 39.6$ & 7.2 \\
\hline September 13th & Super typhoon & $40.5 / 38.3$ & 2.2 & $55.1 / 51.7$ & 3.4 \\
\hline September 14th & Super typhoon & $38.7 / 32.8$ & 5.9 & $41.7 / 34.1$ & 7.6 \\
\hline September 15 th & Super typhoon & $20.8 / 19.8$ & 1 & $28.5 / 21.8$ & 6.7 \\
\hline September 16th & Strong typhoon & $36.4 / 35$ & 1.4 & $52.2 / 44.1$ & 8.1 \\
\hline
\end{tabular}


Table 2. Latitude and longitude of maximum wind speed obtained from CYGNSS and ECMWF reanalysis data.

\begin{tabular}{cccc}
\hline \multicolumn{2}{c}{ CYGNSS } & \multicolumn{2}{c}{ ECMWF Reanalysis Data } \\
\hline Latitude(N) & Longitude(E) & Latitude(N) & Longitude(E) \\
13.8 & 161.8 & 13.7 & 161.3 \\
15.2 & 155.3 & 15.2 & 155.3 \\
14.8 & 148.1 & 15.5 & 146.8 \\
14.2 & 142.2 & 13.8 & 141.2 \\
14.5 & 137.3 & 14.5 & 137.2 \\
15.2 & 131.5 & 15.2 & 131.8 \\
14.4 & 128 & 14.3 & 128 \\
15.8 & 126.1 & 15.2 & 126 \\
21.6 & 116.6 & 21.9 & 116.1 \\
\hline
\end{tabular}

The wind speeds observed by CYGNSS below and above $15 \mathrm{~m} / \mathrm{s}$ were further compared with ECMWF reanalysis data, respectively. The comparison results are shown in Figures 6 and 7 . From Figures 6 and 7 we can see that in general, the CYGNSS wind speeds below $15 \mathrm{~m} / \mathrm{s}$ had a small mean error from the ERA- 5 reanalysis data with $0.05 \mathrm{~m} / \mathrm{s}$; the correlation coefficient was 0.91 and the RMSE was $1.02 \mathrm{~m} / \mathrm{s}$. For the wind speeds above $15 \mathrm{~m} / \mathrm{s}$, the mean error was $1.61 \mathrm{~m} / \mathrm{s}$, the correlation coefficient was 0.90 and the RMSE was $4.36 \mathrm{~m} / \mathrm{s}$ by comparing with the ECMWF reanalysis data. The results show that the accuracy of wind speed inversion of CYGNSS satellite was high at wind speed below $15 \mathrm{~m} / \mathrm{s}$ and the accuracy of high wind speed above $15 \mathrm{~m} / \mathrm{s}$ was reduced.

(a) Correlation analysis of CYGNSS and

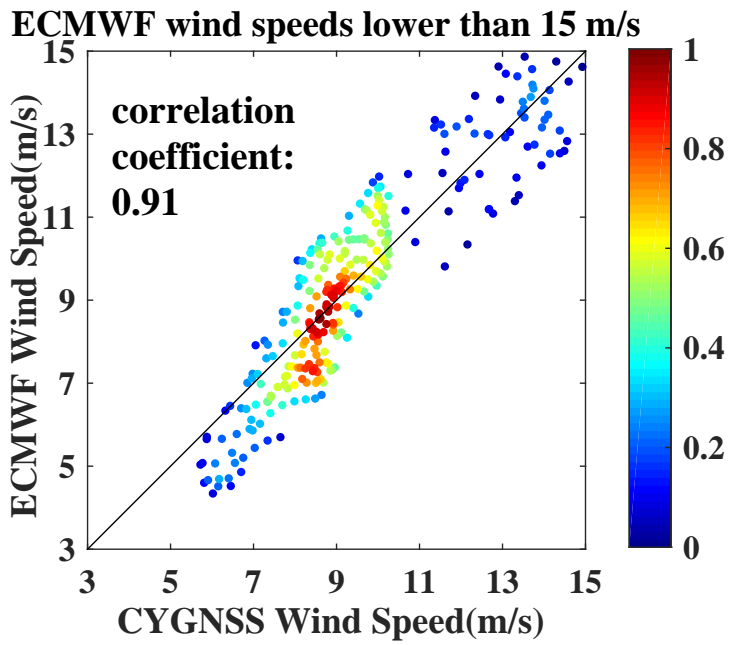

(b) Residual histogram

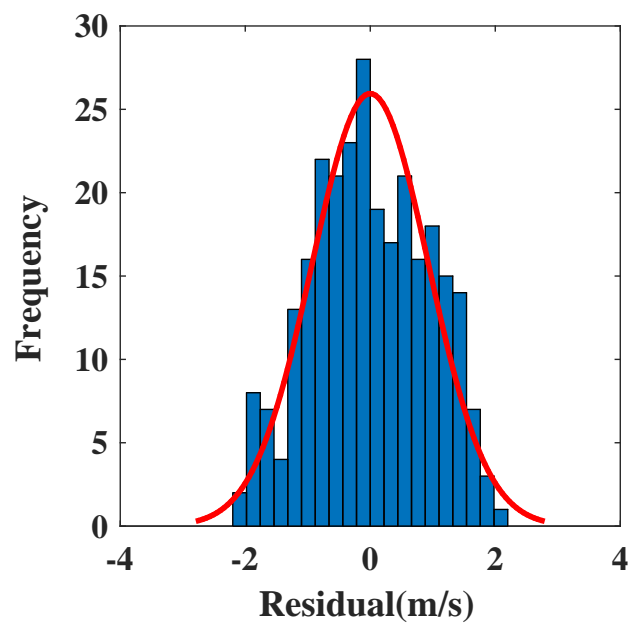

Figure 6. Scatter density plot and residual distribution of CYGNSS and ECMWF wind speeds lower than $15 \mathrm{~m} / \mathrm{s}$. (a) Scatter plot of CYGNSS and ECMWF winds lower than $15 \mathrm{~m} / \mathrm{s}$; (b) CYGNSS and ECMWF wind speed residual distribution histogram. The colors bar (from cool to warm) represents the change of scatter density from small to large values in a given range.

The relative errors of wind speeds below $15 \mathrm{~m} / \mathrm{s}$ and above $15 \mathrm{~m} / \mathrm{s}$ were computed, respectively. When wind speed was lower than $15 \mathrm{~m} / \mathrm{s}$, the average relative error was $9.8 \%$; when wind speed was higher than $15 \mathrm{~m} / \mathrm{s}$, the average relative error was $11.6 \%$.

The statistical characteristics of data errors could be obtained by comparing the wind speed less than $15 \mathrm{~m} / \mathrm{s}$ and greater than $15 \mathrm{~m} / \mathrm{s}$, respectively. In this study, the positive errors indicate that the wind speed of CYGNSS was larger than ECMWF reanalysis wind speed; the negative errors indicate that the wind speed of CYGNSS was less than ECMWF reanalysis wind speed. The color bar represents the data density in a certain range. 
(a) Correlation analysis of CYGNSS and ECMWF wind speeds greater than $15 \mathrm{~m} / \mathrm{s}$

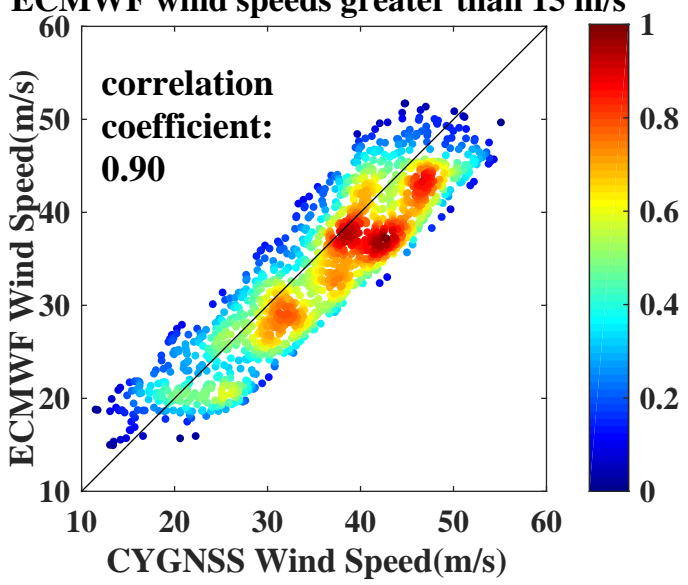

(b) Residual histogram

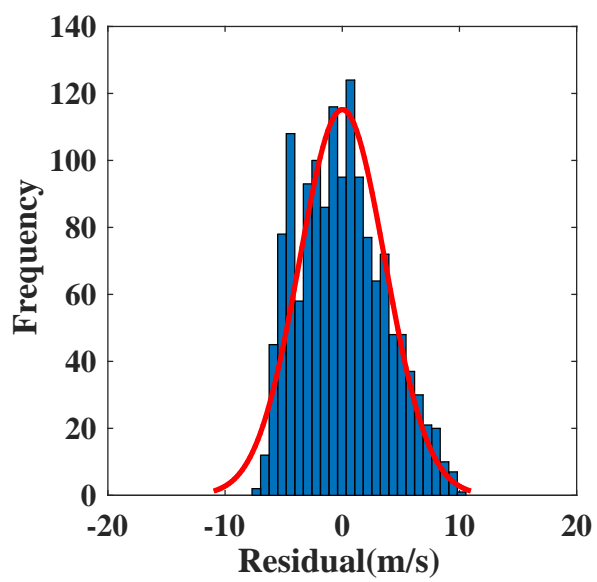

Figure 7. Scatter density plot and residual distribution of CYGNSS and ECMWF wind speeds greater than $15 \mathrm{~m} / \mathrm{s}$. (a) Scatter plot of CYGNSS and ECMWF winds greater than $15 \mathrm{~m} / \mathrm{s}$; (b) CYGNSS and ECMWF wind speed residual distribution histogram. The colors bar (from cool to warm) represents the change of scatter density from small to large values in a given range.

As we can see from Figure 8, when the wind speed was less than $15 \mathrm{~m} / \mathrm{s}$, the number of positive errors and negative errors were very close, which indicates that the wind speed of CYGNSS was very consistent with the ECMWF reanalysis data in general. When the wind speed was greater than $15 \mathrm{~m} / \mathrm{s}$, the highest density of wind speeds errors was generally distributed near $0 \mathrm{~m} / \mathrm{s}$ and $5 \mathrm{~m} / \mathrm{s}$, but the number of positive errors was much larger than the negative errors, indicating that when the wind speed was large, the overall CYGNSS wind speed was larger than the ECMWF reanalysis data. The statistical characteristics of wind speed errors in different regions are shown in Table 3.

(a) Errors distribution with CYGNSS

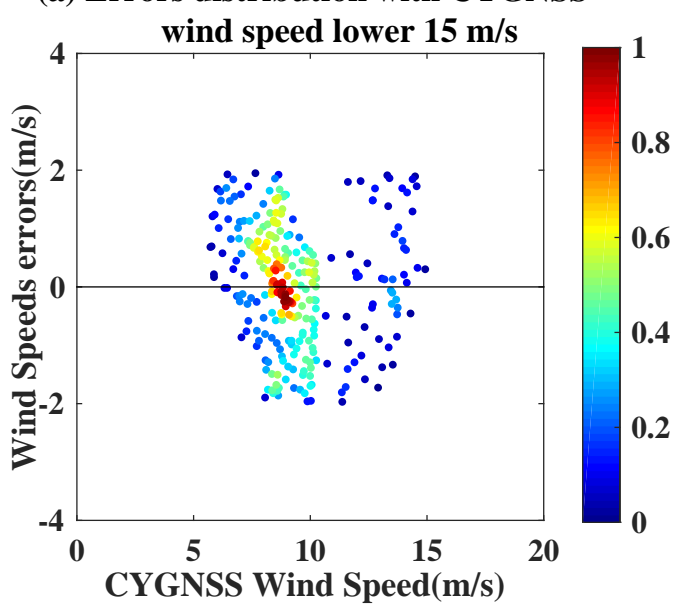

(b) Errors distribution with CYGNSS

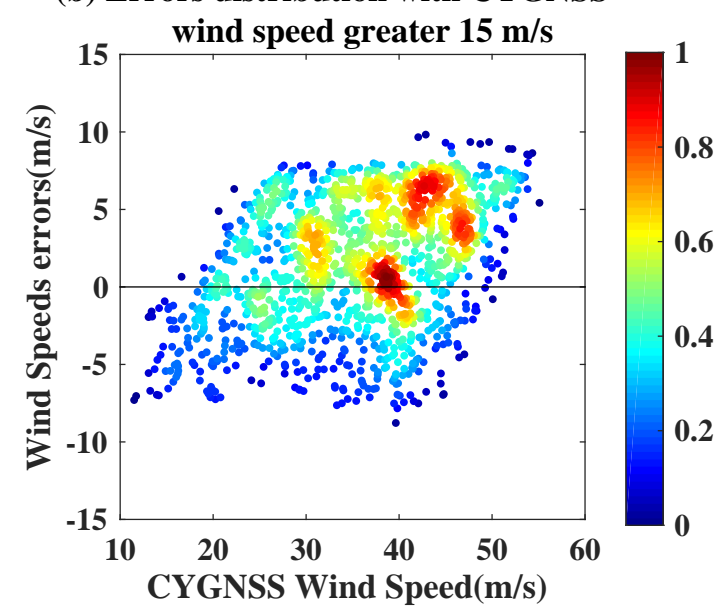

Figure 8. The error distribution of wind speeds less than $15 \mathrm{~m} / \mathrm{s}$ and greater than $15 \mathrm{~m} / \mathrm{s}$. (a) The distribution of errors with the variation of CYGNSS wind speed below $15 \mathrm{~m} / \mathrm{s}$; (b) The distribution of errors with the variation of CYGNSS wind speed above $15 \mathrm{~m} / \mathrm{s}$. The colors bar (from cool to warm) represents the change of scatter density from small to large values in a given range.

Table 3. The mean error and mean absolute error of wind speed between CYGNSS and ECMWF.

\begin{tabular}{ccccc}
\hline Wind Speed & Mean Error (m/s) & Mean Absolute Error $(\mathbf{m} / \mathbf{s})$ & Number of Positive Bias & Number of Negative Bias \\
\hline$<15 \mathrm{~m} / \mathrm{s}$ & 0.05 & 0.84 & 147 & 128 \\
$>15 \mathrm{~m} / \mathrm{s}$ & 1.61 & 3.70 & 939 & 508 \\
\hline
\end{tabular}


In order to analyze the performance of CYGNSS under extreme wind speed, the wind speed sample points of Mangkhut during the development from strong typhoon to super typhoon (wind speed greater than $41.5 \mathrm{~m} / \mathrm{s}$ ) were selected. It can be seen from Figure 9 that the data concentration was not high, and the distribution was relatively scattered. Most of them deviated from the bottom of the diagonal, indicating that when the wind speed was between 40-60 m/s, the overall CYGNSS wind speed was larger than the ECMWF reanalysis data and the errors between them were further increased when compared to the low wind speed. Figure $8 \mathrm{~b}$ shows that the wind speeds from strong typhoons to super typhoons have more positive errors, which indicates that in high wind speed ranges greater than $40 \mathrm{~m} / \mathrm{s}$, the accuracy of CYGNSS decreased faster than at lower wind speeds.

(a) Correlation analysis of CYGNSS and

ECMWF wind speeds greater than $41.5 \mathrm{~m} / \mathrm{s}$

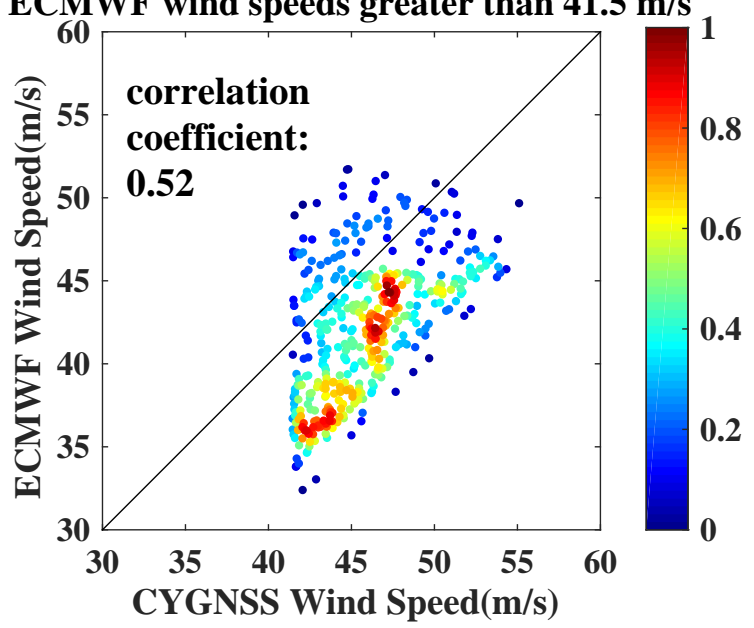

(b) Residual histogram

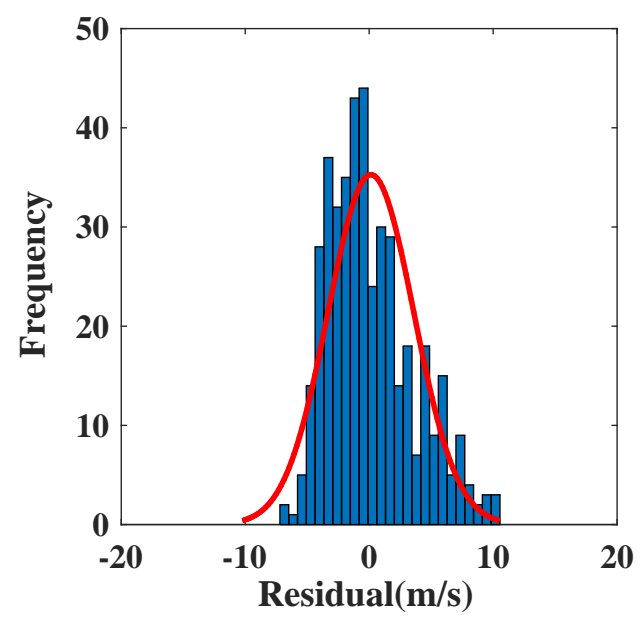

Figure 9. Scatter density plot and residual distribution of CYGNSS and ECMWF wind speeds greater than $41.5 \mathrm{~m} / \mathrm{s}$. (a) Scatter plot of CYGNSS and ECMWF winds greater than $41.5 \mathrm{~m} / \mathrm{s}$; (b) CYGNSS and ECMWF wind speed residual distribution histogram. The colors bar (from cool to warm) represents the change of scatter density from small to large values in a given range.

The statistics resulted show that when a typhoon reaches the level of strong typhoon or above, the RMSE of CYGNSS and ECMWF was $5.07 \mathrm{~m} / \mathrm{s}$, the mean error was $3.57 \mathrm{~m} / \mathrm{s}$ and the correlation coefficient was 0.52 . When the wind speed was larger than $41.5 \mathrm{~m} / \mathrm{s}$, the average relative error was $11.0 \%$. This average relative error confirmed that the higher the wind speed was, the lower the CYGNSS precision was. However, within the dynamic range of $41.5 \mathrm{~m} / \mathrm{s}$ and above, the change of average relative error was still relatively low and there was no particularly large deviation value.

\subsection{Discussion}

The CYGNSS provided wind speed products are compared with ECMWF reanalysis data in this paper. When the wind speed was lower than $15 \mathrm{~m} / \mathrm{s}$, the RMSE and mean error of CYGNSS derived wind speed are $1.02 \mathrm{~m} / \mathrm{s}$, and $0.05 \mathrm{~m} / \mathrm{s}$, respectively, and the correlation coefficient between two wind speed data sets reach 0.91 . Whereas, the RMSE of CYGNSS's wind speed at higher wind speed range is $4.36 \mathrm{~m} / \mathrm{s}$, mean error is $1.61 \mathrm{~m} / \mathrm{s}$ and the correlation coefficient reaches 0.90 . This is mainly due to the fact that the ocean scattering cross section lost the sensitivity to accurately respond to the change of heavy wind speed and the random error of obtaining DDM signal was increased. Therefore, the error started to increase slowly when the wind speed was higher than $15 \mathrm{~m} / \mathrm{s}$. The higher the wind speed is, the greater the error is. When compared the wind speed of CYGNSS with ECMWF reanalysis data, the sample points are divided into the wind speed below $15 \mathrm{~m} / \mathrm{s}$ and wind speed above $15 \mathrm{~m} / \mathrm{s}$ and the comparison results were also consistent with the actual situation. 
In order to verify the accuracy of CYGNSS in actual super typhoons, the wind speed during different typhoon development stage are compared. When the wind speed is greater than $41.5 \mathrm{~m} / \mathrm{s}$, the RMSE of CYGNSS and ECMWF reanalysis data is $5.07 \mathrm{~m} / \mathrm{s}$, the mean error is $3.57 \mathrm{~m} / \mathrm{s}$ and the correlation coefficient was 0.52 , the average relative error account $11.0 \%$. Compared to the uncertainty of low wind speed, the retrieval error of CYGNSS increased at high wind speed further increases, and the range of error is similar to the expected error range of CYGNSS.

In the future, the influence of satellite related parameters on inversion results and the ocean topographic factors on the typhoon will be further analyzed. Moreover, at higher wind speed, the original DDM signal generated a large number of random errors because the ocean scattering cross section could not accurately reflect the wind speed change. This random error was transmitted during the subsequent signal processing and reduced the inversion accuracy of the wind speed. If the error effect of the signal under high wind speed conditions could be removed, the accuracy of high wind speed could be improved. Furthermore, with the development of other GNSS constellations [23,24], high resolution will be expected in the future.

\section{Conclusions}

In this study, the accuracy of CYGNSS wind speed during the 2018 Typhoon of Mangkhut was evaluated by comparing with ERA-5 reanalysis data. The results show that in the life cycle of the super typhoon, the overall mean error between CYGNSS wind speed and ERA-5 reanalysis data is $1.36 \mathrm{~m} / \mathrm{s}$, the correlation coefficient is 0.96 , and the overall RMSE is $4.12 \mathrm{~m} / \mathrm{s}$. At different wind speed ranges, the accuracy of the CYGNSS is different. Compared with the ECMWF reanalysis wind product, when the wind speed is below $15 \mathrm{~m} / \mathrm{s}$, RMSE of CYGNSS derived wind speed is $1.02 \mathrm{~m} / \mathrm{s}$, the mean error is $0.05 \mathrm{~m} / \mathrm{s}$, the correlation coefficient is 0.91 and the average relative error is $9.8 \%$. However, when the wind speed is above $15 \mathrm{~m} / \mathrm{s}$, RMSE is $4.36 \mathrm{~m} / \mathrm{s}$, the mean error is $1.61 \mathrm{~m} / \mathrm{s}$, the correlation coefficient reaches 0.90 and the average relative error is $11.6 \%$. When the typhoon increased to be a strong typhoon or a super typhoon and the wind speed is greater than $41.5 \mathrm{~m} / \mathrm{s}$, the RMSE of CYGNSS wind speed is $5.07 \mathrm{~m} / \mathrm{s}$, the mean error is $3.57 \mathrm{~m} / \mathrm{s}$, the correlation coefficient is 0.52 and the average relative error is $11.0 \%$. The CYGNSS derived wind product demonstrated that GNSS-R has an excellent capability in typhoon monitoring. In the future, it could play a great role in the measurement of sea surface wind field and typhoon forecasting.

Author Contributions: Data curation, H.L.; funding acquisition, S.J.; methodology, H.L. and S.J.; resources, H.L.; software, H.L.; supervision, S.J.; writing-original draft, H.L.; writing—review and editing, S.J. and Q.Y. All authors have read and agreed to the published version of the manuscript.

Funding: This work was funded by the strategic priority research program project of the Chinese Academy of Sciences, grant number XDA23040100; Shanghai Leading Talent Project, Jiangsu Province Distinguished Professor Project, grant number \#R2018T20 and Startup Foundation for Introducing Talent of NUIST.

Acknowledgments: We thank the NASA, China typhoon network, the National Meteorological Center of CMA, the Hong Kong Observatory and European Center for Medium-Range Weather Forecasts (ECMWF) for providing the data.

Conflicts of Interest: The authors declare no conflicts of interest. The funders had no role in the design of the study; in the collection, analyses or interpretation of data; in the writing of the manuscript; or in the decision to publish the results.

\section{References}

1. Dengrong, Z.; Wang, J.; Zhang, Y. Review of typhoon monitoring technology based on remote sensing satellite data. Remote Sens. Technol. Appl. 2013, 28, 994-999.

2. Yu, J.H.; Tang, J.X.; Dai, Y.H.; Yu, B.Y. Analyses in Errors and Their Causes of Chinese Typhoon Track Operational Forecasts. Meteorol. Mon. 2012, 38, 695-700.

3. Lei, X.T.; Li, Y.P.; Yu, R.L. A new generation of regional air sea wave coupled typhoon prediction system. Acta Oceanol. 2019, 41, 123-134. 
4. Rogers, R.F.; Reasor, P.D.; Lorsolo, S. Airborne Doppler observations of the inner-core structural differences between intensifying and steady-state tropical cyclones. Mon. Weather Rev. 2013, 141, 2970-2991. [CrossRef]

5. Jin, S.G.; Su, K. PPP models and performances from single- to quad-frequency BDS observations. Satell. Navig. 2020, 1, 16. [CrossRef]

6. Jin, S.G.; Komjathy, A. GNSS reflectometry and remote sensing: New objectives and results. Adv. Space Res. 2010, 46, 111-117. [CrossRef]

7. Jin, S.G.; Feng, G.; Gleason, S. Remote sensing using GNSS signals: Current status and future directions. Adv. Space Res. 2011, 47, 1645-1653. [CrossRef]

8. Dong, Z.N.; Jin, S.G. Evaluation of spaceborne GNSS-R retrieved ocean surface wind speed with multiple datasets. Remote Sens. 2019, 11, 2747. [CrossRef]

9. Jin, S.G.; Cardellach, E.; Xie, F. GNSS Remote Sensing: Theory, Methods and Applications; Springer: Amsterdam, The Netherlands, 2014; 276p.

10. Morris, M.; Ruf, C.S. Estimating tropical cyclone integrated kinetic energy with the CYGNSS satellite constellation. J. Appl. Meteorol. Climatol. 2016, 56, 235-245. [CrossRef]

11. Cui, Z.Q.; Zhao, X.P.; Tallapragada, V.; Atlas, R.; Ruf, C.S. A preliminary impact study of CYGNSS ocean surface wind speeds on numerical simulations of hurricanes. Geophys. Res. Lett. 2019, 46, 2984-2992. [CrossRef]

12. Hoover, K.E.; Mecikalski, J.R. Use of an End-to-End-Simulator to analyze CYGNSS. J. Atmos. Ocean. Technol. 2017, 35, 35-55. [CrossRef] [PubMed]

13. Saïd, F.; Katzberg, S.J.; Soisuvarn, S. Retrieving Hurricane Maximum Winds Using Simulated CYGNSS Power-Versus-Delay Waveforms. IEEE J. STARS 2017, 10, 3799-3809. [CrossRef]

14. Shi, X.Z.; Zhao, X.P. Impact of CYGNSS ocean surface wind speeds on numerical simulations of a hurricane in observing system simulation experiments. J. Atmos. Ocean. Technol. 2017, 34, 375-383.

15. Alpert, P.; Neeman, B.U.; Shay-El, Y. Climatological analysis of Mediterranean cyclones using ECMWF data. J. Tellus 1990, 42, 65-77. [CrossRef]

16. Annane, B.; McNoldy, B.; Leidner, S.M.; Hoffman, R.; Atlas, R.; Majumdar, S.J. A study of the HWRF analysis and forecast impact of realistically simulated CYGNSS observations assimilated as scalar wind speeds and as VAM wind vectors. J. Mon. Weather Rev. 2018, 146, 2221-2236. [CrossRef]

17. Ruf, C.S. New ocean winds satellite mission to probe hurricanes and tropical convection. Meteorol. Soc. 2015, 97, 835-895. [CrossRef]

18. Clarizia, M.P.; Ruf, C.S.; Jales, G.P. Spaceborne GNSS-R minimum variance wind speed estimator. J. IEEE Trans. Geosci. Remote Sens. 2014, 52, 6829-6843. [CrossRef]

19. Clarizia, M.P.; Ruf, C.S. Wind speed retrieval algorithm for the Cyclone Global Navigation Satellite System (CYGNSS) mission. IEEE Trans. Geosci. Remote Sens. 2016, 54, 4419-4432. [CrossRef]

20. Ruf, C.S.; Balasubramaniam, R. Development of the CYGNSS Geophysical Model Function for Wind Speed. IEEE J. Sel. Top. Appl. Earth Obs. Remote Sens. 2019, 12, 66-77. [CrossRef]

21. Ruf, C.S.; Chang, P.; Clarizia, M.P.; Gleason, S.; Jelenak, Z. CYGNSS handbook. In Cyclone Global Navigation Satellite Systems; NASA: Ann Arbor, MI, USA, 2016; Volume 4, pp. 1-155. ISBN 978-1-60785-380-0.

22. Olauson, J. ERA5: The new champion of wind power modelling? J. Renew. Energy 2018, 126, $322-331$. [CrossRef]

23. Jin, S.G.; Zhang, Q.; Qian, X. New progress and application prospects of Global Navigation Satellite System Reflectometry (GNSS+R). ACTA Geod. Cartograph. Sin. 2017, 46, 1389-1398.

24. Jin, S.G.; Qian, X.; Wu, X. Sea level change from BeiDou Navigation Satellite System-Reflectometry (BDS-R): First results and evaluation. Global Planet. Change 2017, 149, 20-25. [CrossRef]

(C) 2020 by the authors. Licensee MDPI, Basel, Switzerland. This article is an open access article distributed under the terms and conditions of the Creative Commons Attribution (CC BY) license (http://creativecommons.org/licenses/by/4.0/). 